\title{
Detection of marine aerosols with IRS P4-Ocean Colour Monitor
}

\author{
InDRANi DAS*, M Mohan* and K KRISHnAmoORTHY** \\ * Marine Science and Coastal Environment Division, Space Applications Centre (ISRO), \\ Ahmedabad 380 015, India \\ e-mail:dindrani@rediffmail.com_mannilmohan@yahoo.com \\ ** Space Physics Laboratory, Vikram Sarabhai Space Centre (ISRO), Trivandrum 695 022, India.
}

\begin{abstract}
The atmospheric correction bands 7 and $8(765 \mathrm{~nm}$ and $865 \mathrm{~nm}$ respectively) of the Indian Remote Sensing Satellite IRS P4-OCM (Ocean Colour Monitor) can be used for deriving aerosol optical depth (AOD) over the oceans. A retrieval algorithm has been developed which computes the AOD using band 7 data by treating the ocean surface as a dark background after removing the Rayleigh path radiance in the sensor-detected radiances. This algorithm has been used to detect marine aerosol distributions at different coastal and offshore locations around India.

A comparison between OCM derived AOD and the NOAA operational AOD shows a correlation $\sim 0.92$ while that between OCM derived AOD and the ground-based sun photometer measurements near the coast of Trivandrum shows a correlation of $\sim 0.90$.
\end{abstract}

\section{Introduction}

Aerosols are responsible for a number of physical effects in the atmosphere, the most important being modifying the atmospheric radiation balance (Coakley et al 1983) by reflecting away the incoming solar radiation (albedo effect) and retaining the outgoing terrestrial radiation (greenhouse effect). Aerosols also reduce visibility, cause air pollution and influence the cloud formation microphysics by acting as condensation nuclei.

Aerosols play a major role in the radiative coupling of land, ocean and the atmosphere (Charlson et al 1987). In recent years, there have been attempts to assess the impact of aerosols on the earth's climate through numerical prediction experiments. Some of these studies have indicated that on a global scale, the aerosol albedo effect can offset the greenhouse forcing by about 20-40\% [WMO 1996; Penner et al (IPCC) 2001]. Whereas numerical experiments on regional scales have shown the aerosols to reduce vertical mixing in the tropical atmosphere (through modifica- tion of the vertical temperature profile), narrow the ITCZ (Inter Tropical Convergence Zone) by slowing down the trade winds and also weaken the monsoon by reducing the land-sea temperature contrast (Galindo 1984; Kaufman et al 1997), such numerical experiments though highly instructive, have not so far shown among themselves quantitative agreements in their conclusions due to the lack of realistic synoptic scale information on the aerosol parameters introduced into the models. For instance, there is no global information on the spatial distributions of aerosol optical depths, single scattering albedo, scattering phase function, particle size distribution, vertical profile, sources and sinks, etc. Whatever information is available currently on aerosols is obtained through landbased observations (sun photometers, Anderson impacters, lidars, etc.) and very rarely through balloon borne, ship borne, aircraft borne and rocket borne observations. These observations are of limited spatial and temporal extent and are highly inadequate for introduction into climate prediction models. Absence of aerosol data is particularly

Keywords. IRS P4-OCM; Ocean Colour Monitor; aerosol optical depth; marine aerosols; aerosol plumes.

Proc. Indian Acad. Sci. (Earth Planet. Sci.), 111, No. 4, December 2002, pp. 425-435 
severe over the oceans which cover nearly $\sim 71 \%$ of the earth's surface.

Satellites, with their capability for large area coverage and short term repeativity, are the most ideal means for acquiring global information on aerosols (Joseph 1984; Kaufman et al 1997). The currently orbiting ocean colour sensors IRS P3MOS-B, IRS P4-OCM and SeaWiFS, though primarily meant for ocean colour remote sensing, have the additional capability for monitoring the global distribution of marine aerosols.

In order to correct for atmospheric interference in the remote sensing of oceanic constituents, ocean colour sensors are generally equipped with additional channels or bands called atmospheric correction bands that operate in wavelengths above $\sim 700 \mathrm{~nm}$. These bands, while fulfilling atmospheric correction can indirectly provide information on atmospheric aerosols. The method of derivation of AOD from the radiance data of atmospheric correction bands is described in section 2. Based on this procedure, an algorithm was developed to derive AOD from IRS P4-OCM band-7 data. In section 3, we examine the sensitivity of this algorithm to various parameters used for characterising the aerosol model used in the algorithm. The images of the AOD distributions at different offshore sites around India derived from OCM data are presented in section 4.

The OCM detected AOD was compared with the NOAA operational AOD over the offshore areas of the Arabian Sea and the Bay of Bengal and also with the ground measurements at the coastal site of Trivandrum. These results are presented in sections 5 and 6 respectively. In section 7 , we summarise the major conclusions of this study.

\section{Estimation of AOD from atmospheric correction band radiances of ocean colour sensors}

The atmospheric correction bands of ocean colour sensors operate in wavelengths above $\sim 700 \mathrm{~nm}$. In these wavelengths, water is a strong absorber of radiation and acts as a dark background for a space borne ocean colour remote sensor (Gordon 1997). The sensor radiance detected in these wavelengths is entirely due to the backscatter of solar radiation from the atmosphere. This radiance, called the atmospheric path radiance is just the sum of the Rayleigh and the aerosol path radiances produced by the scattering of light by air molecules and aerosols respectively. One can thus split the sensor detected radiance as

$$
L_{t}=L_{a}+L_{r}
$$

where

$$
\begin{aligned}
L_{t}= & \text { sensor detected radiance. } \\
L_{r, a}= & F_{0} /\left(4 \pi \cos \theta_{v}\right) \cdot w_{0 r, a} \cdot \tau_{r, a} \cdot p_{r, a} \\
& \text { Rayleigh/aerosol path radiance. } \\
F_{0}= & \text { extra terrestrial solar flux. } \\
\theta_{v}= & \text { satellite viewing angle. } \\
w_{0 r}= & \text { Rayleigh single scattering albedo } \\
& (\sim 1.0) . \\
w_{0 a}= & \text { aerosol single scattering albedo. } \\
\tau_{r, a}= & \text { Rayleigh/aerosol optical depth. } \\
p_{r, a}= & \text { a function related to the Rayleigh/ } \\
& \text { aerosol scattering phase function. }
\end{aligned}
$$

The function $p_{r, a}$ is related to the Rayleigh/ aerosol scattering phase function (Doerffer 1992) as

$$
p_{r, a}(\gamma)=P_{r, a}\left(\gamma^{-}\right)+\left[R\left(\theta_{v}\right)+R\left(\theta_{s}\right)\right] P_{r, a}\left(\gamma^{+}\right),
$$

where $R$ is the Fresnel reflectance of the water surface, $\theta_{s}$ is the solar zenith angle and $\gamma^{ \pm}$is the forward/backward scattering angle. The Rayleigh phase function scattering is given by

$$
P_{r}\left(\gamma^{ \pm}\right)=(3 / 4)\left[1+\cos ^{2}\left(\gamma^{ \pm}\right)\right] .
$$

Following Doerffer (1992), one can approximate the scattering phase function for marine aerosols by a two term Heyney-Greenstein (HG) phase function of the form

$$
P_{a}\left(\gamma^{ \pm}\right)=A f\left(\gamma^{ \pm}, g_{1}\right)+(1-A) f\left(\gamma^{ \pm}, g_{2}\right),
$$

where

$$
f\left(\gamma^{ \pm}, g\right)=\left(1-g^{2}\right) /\left[\left(1+g^{2}-2 g \cos \gamma^{ \pm}\right)^{3 / 2}\right]
$$

with $A=0.985, g_{1}=0.8$ and $g_{2}=0.5$ for marine aerosols (Sturm 1980; Doerffer 1992). The forward/backward scattering angles are related to the sensor viewing and solar illumination directions through:

$$
\cos \gamma^{ \pm}= \pm \cos \theta_{v} \cos \theta_{s}-\sin \theta_{v} \sin \theta_{s} \cos \phi
$$

where $\phi$ is the azimuth difference between the sensor viewing and solar illumination directions. Further, in the expression (2), Fresnel reflectance (for unpolarised radiation) is given by

$$
\begin{aligned}
R\left(\theta_{i}\right)= & 0.5\left[\sin ^{2}\left(\theta_{i}-\theta_{j}\right) / \sin ^{2}\left(\theta_{i}+\theta_{j}\right)\right. \\
& \left.+\tan ^{2}\left(\theta_{i}-\theta_{j}\right) / \tan ^{2}\left(\theta_{i}+\theta_{j}\right)\right],
\end{aligned}
$$

where $\theta_{j}$ is determined through the relation (Snell's law)

$$
\sin \theta_{i} / \sin \theta_{j}=n,
$$

where $n$ is the refractive index of water.

Using the relations (1)-(7) and assuming $w_{0 a} \approx$ 1.0 for marine aerosols (Doerffer 1992), we can determine the aerosol optical depth (AOD) from the sensor detected radiance as

$$
\tau_{a}=\left(L_{t}-L_{r}\right) /\left[F_{0} /\left(4 \pi \cos \theta_{v}\right) \cdot p_{a}\right] .
$$




\section{Sensitivity of AOD retrieval to the aerosol characterisation parameters}

The sensitivity of the AOD retrieval to the aerosol characterisation parameters $g_{1}, g_{2}$ and $A$ (of the HG phase function), the single scattering albedo $w_{0 a}$ and also to error in the aerosol path radiance $L_{a}\left(=L_{t}-L_{r}\right)$ were examined by computing the percentage deviation in AOD produced by small variations in the values of these parameters.

All the variations considered were centred around the values appropriate for marine aerosols mentioned earlier and they ranged from $-10 \%$ to $+10 \%$ in the case of $g_{1}, g_{2}$ and $A$, from $-10 \%$ to $0 \%$ in the case of $w_{0 a}$ and from $-10 \%$ to $+10 \%$ in the case of $L_{a}$. The satellite viewing and sun illumination angles used in these computations were corresponding to a sub satellite point in the Arabian Sea at the equatorial crossing on the day, March 21st, 1999.

The results are shown in figures $1(\mathrm{a})-(\mathrm{e})$. In figures 1 (a) and (b) one can see that the AOD deviation has a pronounced nonlinear dependence on variations in $g_{1}$ and $g_{2}$ and the sensitivity to $g_{1}$ is more than that to $g_{2}$ by a factor $\sim 100$. The range of AOD deviation is from $-8.78 \%$ to $38.21 \%$ in the case of $g_{1}$ while it is from $-6.39^{*} 10^{-2}$ to $3.37^{*} 10^{-2}$ in the case of $g_{2}$.
Figure 1(c) shows the AOD deviation with respect to changes in $A$ to be nearly linear and small, that is, from $-1.31 \%$ to $1.35 \%$ for the range of change considered. In the case of $w_{0 a}$, a $10 \%$ decrease brings about an $11.11 \%$ increase in AOD as shown in figure 1(d) because of the inverse relationship. As far as $L_{a}$ is concerned, any error in it produces a proportional change in AOD as shown in figure $1(\mathrm{e})$.

\section{Detection of aerosols with IRS P4-OCM}

The sensor specifications of the Indian Remote Sensing Satellite IRS P4-OCM (Ocean Colour Monitor) are given in table 1 . One can see that the bands $b_{7}$ and $b_{8}$ have wavelengths above $\sim 700 \mathrm{~nm}$ and are suitable for the detection of aerosols over the oceans.

Based on the procedure described in section 2, an algorithm was developed to estimate the marine AOD from the band-7 radiances of OCM after masking the clouds. Clouds were masked using a predefined threshold corresponding to an albedo of 0.009 in band $8(865 \mathrm{~nm})$ of OCM. This number was arrived at after analysing a number of images and it agrees with the cloud detection threshold used in SeaWiFS processing (McClain et al 1995).

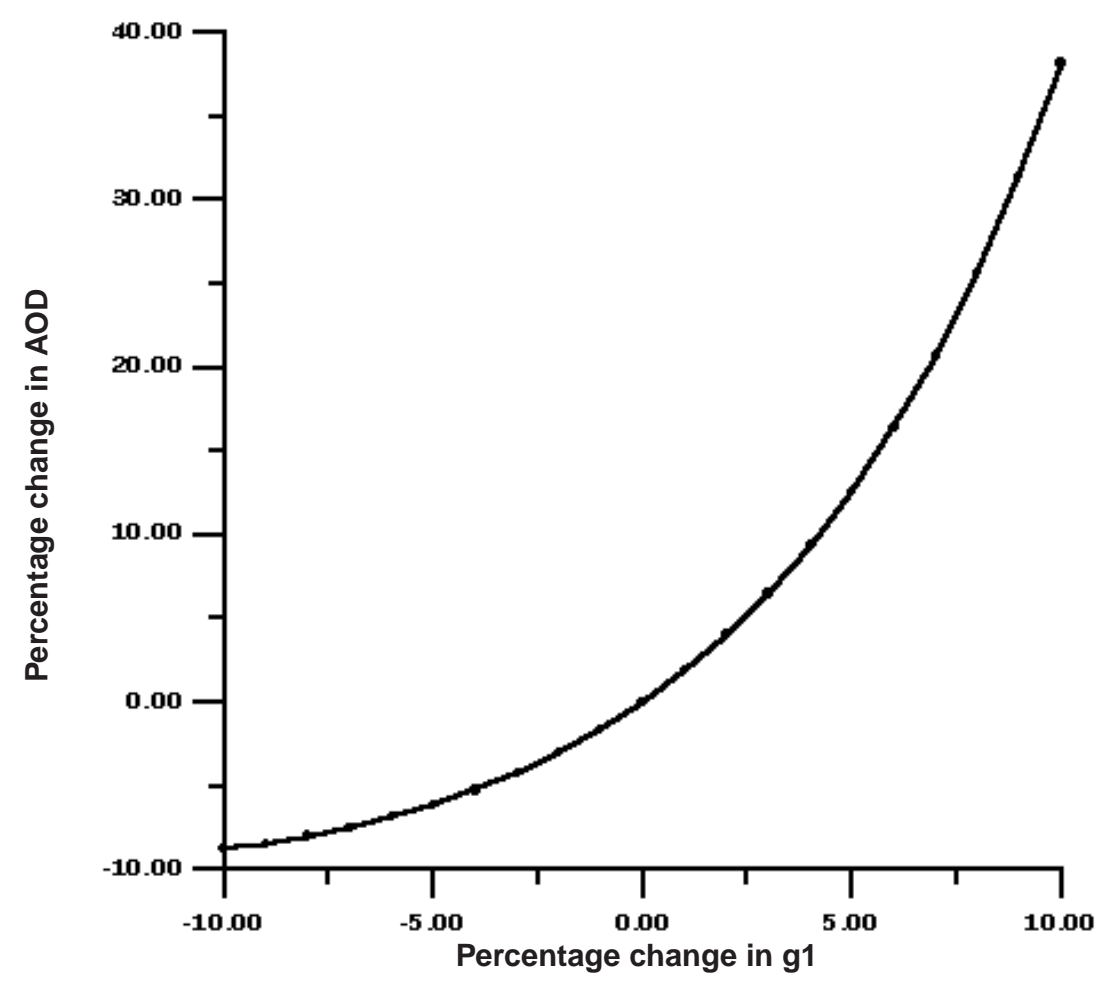

(a)

Figure 1(a). Sensitivity of the values of $g_{1}$ on the derived AOD. 


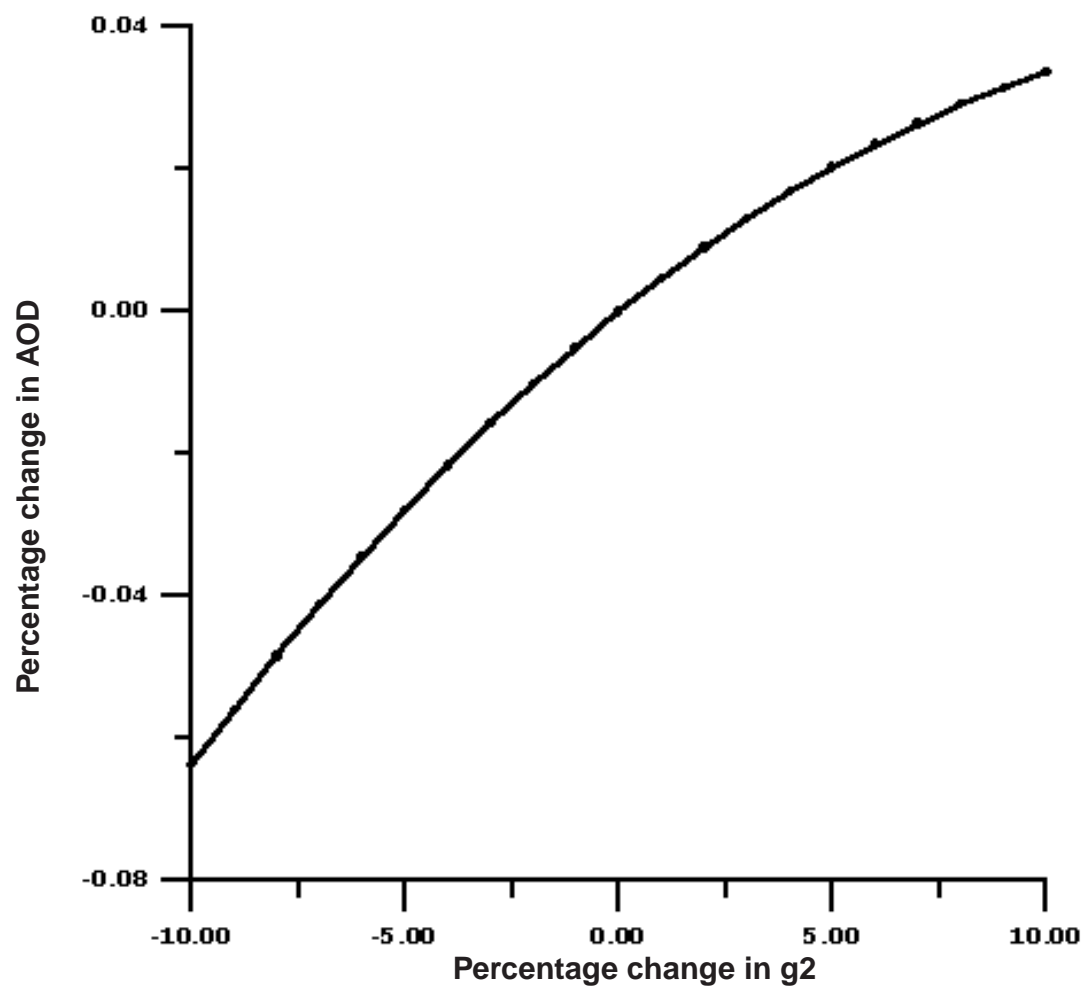

(b)

Figure 1(b). Sensitivity of the values of $g_{2}$ on the derived AOD.

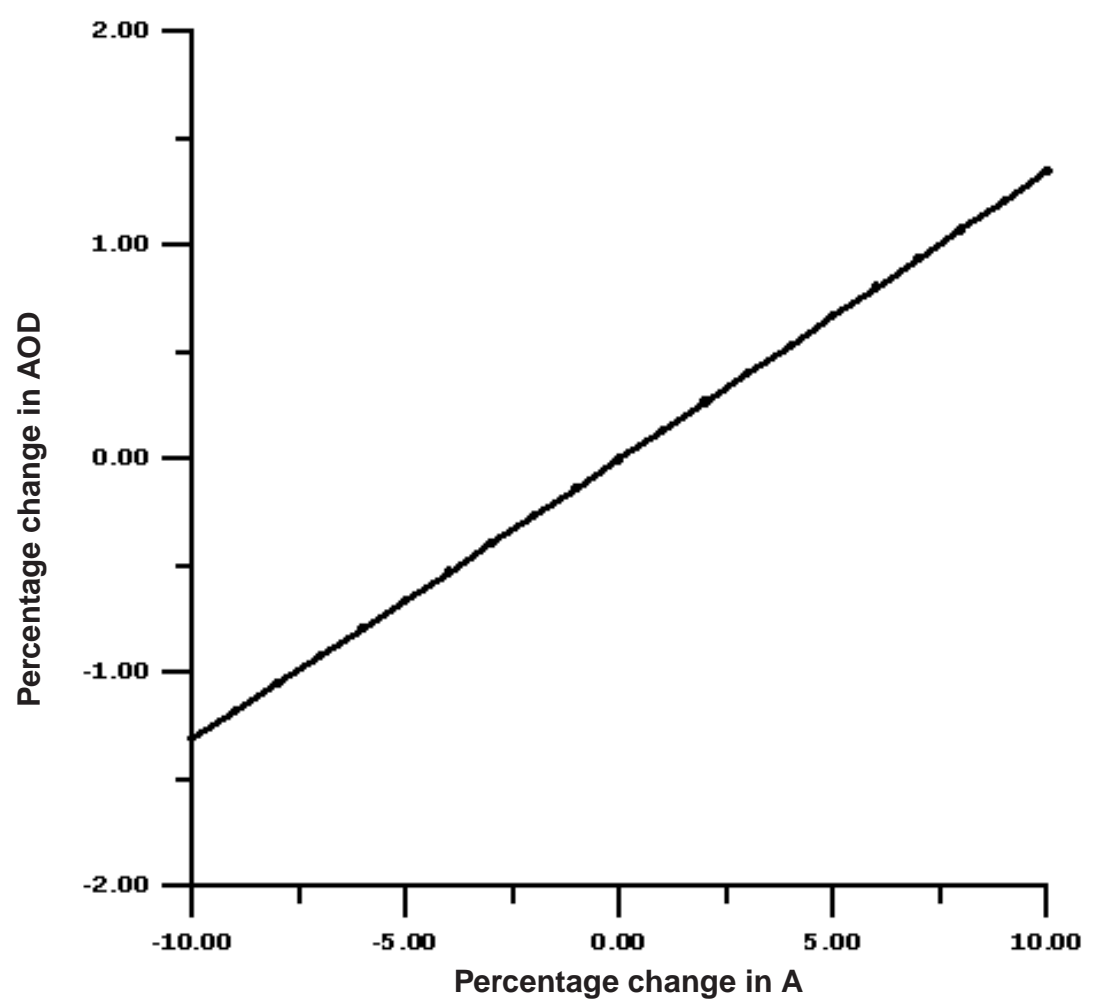

(c)

Figure 1(c). Sensitivity of the values of $A$ on the derived AOD. 


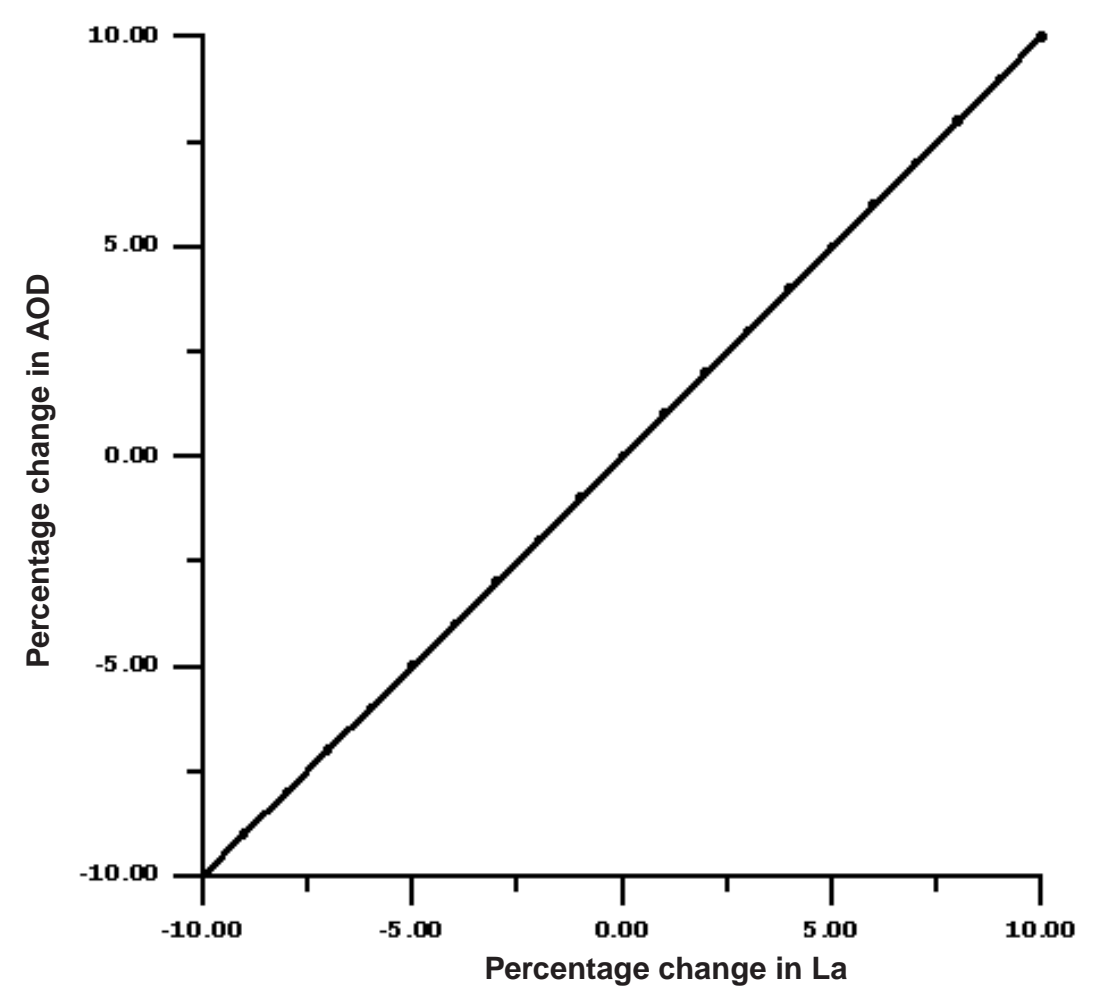

(d)

Figure 1(d). Sensitivity of the values of $L_{a}$ on the derived AOD.

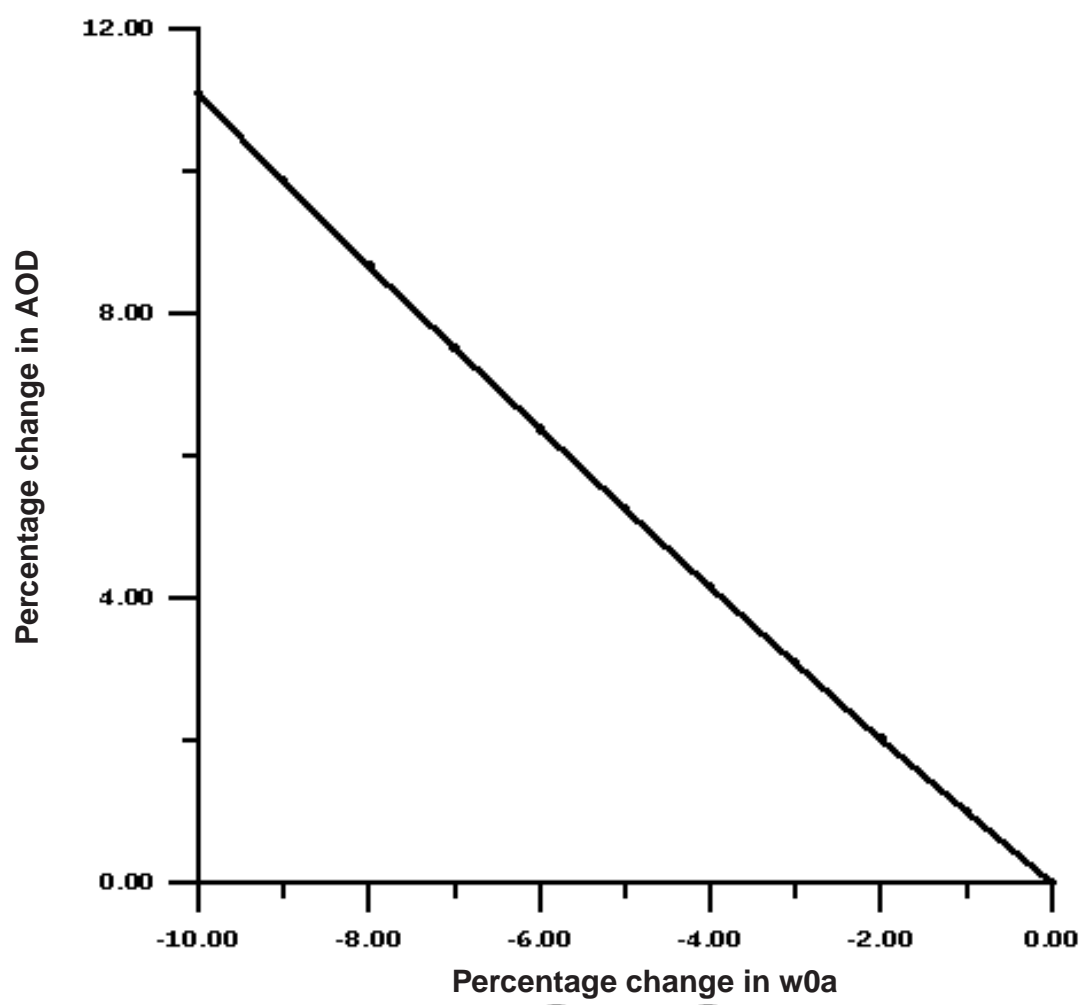

(e)

Figure 1(e). Sensitivity of the values of $w_{0 a}$ on the derived AOD. 
Table 1. Sensor specifications of IRS P4-OCM.

\begin{tabular}{lc}
\hline Sensor parameters & IRS P4-OCM \\
\hline GIFOV $(\mathrm{km})$ & 0.360 \\
Swath $(\mathrm{km})$ & 1420 \\
Repeativity (days) & 2 \\
Equatorial crossing & 12 noon \\
Maximum scan plane tilt (deg) & \pm 20 \\
Spectral bands (nm) & $\left(b_{1}\right) 412 \pm 10$ \\
& $\left(b_{2}\right) 443 \pm 10$ \\
& $\left(b_{3}\right) 490 \pm 10$ \\
& $\left(b_{4}\right) 520 \pm 10$ \\
& $\left(b_{5}\right) 555 \pm 10$ \\
& $\left(b_{6}\right) 670 \pm 10$ \\
& $\left(b_{7}\right) 765 \pm 20$ \\
Radiometric quantisation & $\left(b_{8}\right) 865 \pm 20$ \\
SNR & 12 bits \\
\hline
\end{tabular}

Figures 2 and 3 show the AOD distribution over the Arabian Sea off Goa (November 15th, 1999) and off Trivandrum (January 7th, 2000) respectively. The land surface and clouds have been masked as dark in these images. The small white scattered patches in figure 3 are cloud edges or optically thin clouds. The increased values of AOD close to the coast is due to the bottom reflection in shallow waters or scattering of radiation by suspended particulates in the turbid waters. At these points, the AOD values may not be realistic since the condition $L_{w}=0$ assumed in the retrieval is not strictly valid in shallow/turbid waters. In both these figures the AOD distribution appears as long, continuous light shaded streaks originating from land and extending into the ocean in a south-westward direction depicting the situation of aerosols being blown into the ocean by the prevailing northwesterly winds of the season.

Figure 4 (a) and (b) shows plumes of aerosols off Mumbai coast detected on two successive dates of OCM pass; December 13th and 15th, 1999 respectively. These aerosols are probably of industrial origin, which have been rendered observable by the northwesterly winds, which have blown them towards the ocean. In these figures, one can notice a number of finer details in the

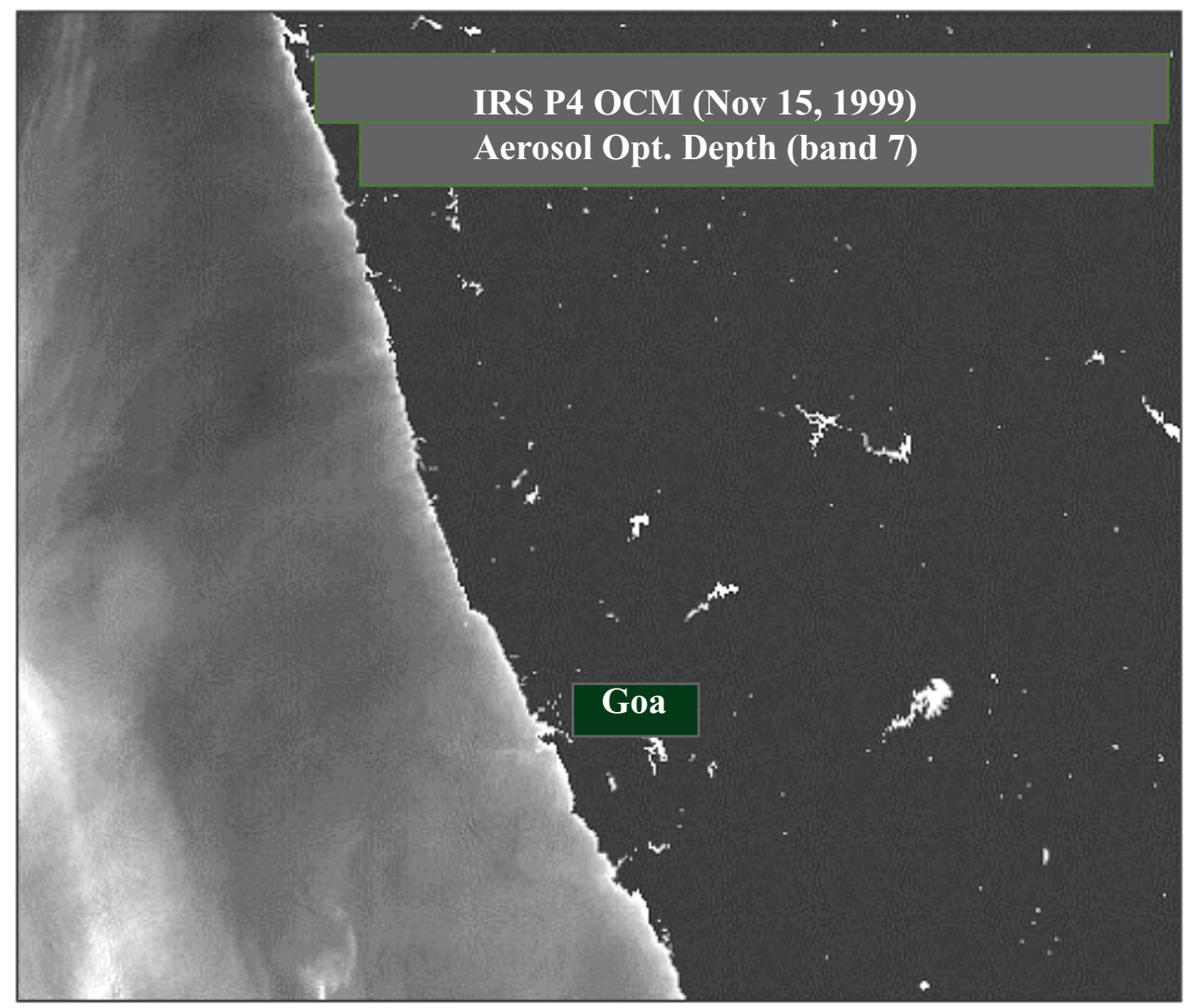

MO(INACISRO

0.0

0.5

Figure 2. Aerosol optical depth detected by IRS P4-OCM off Goa coast on November 15th, 1999. The highly reflecting land surface is masked as dark. 


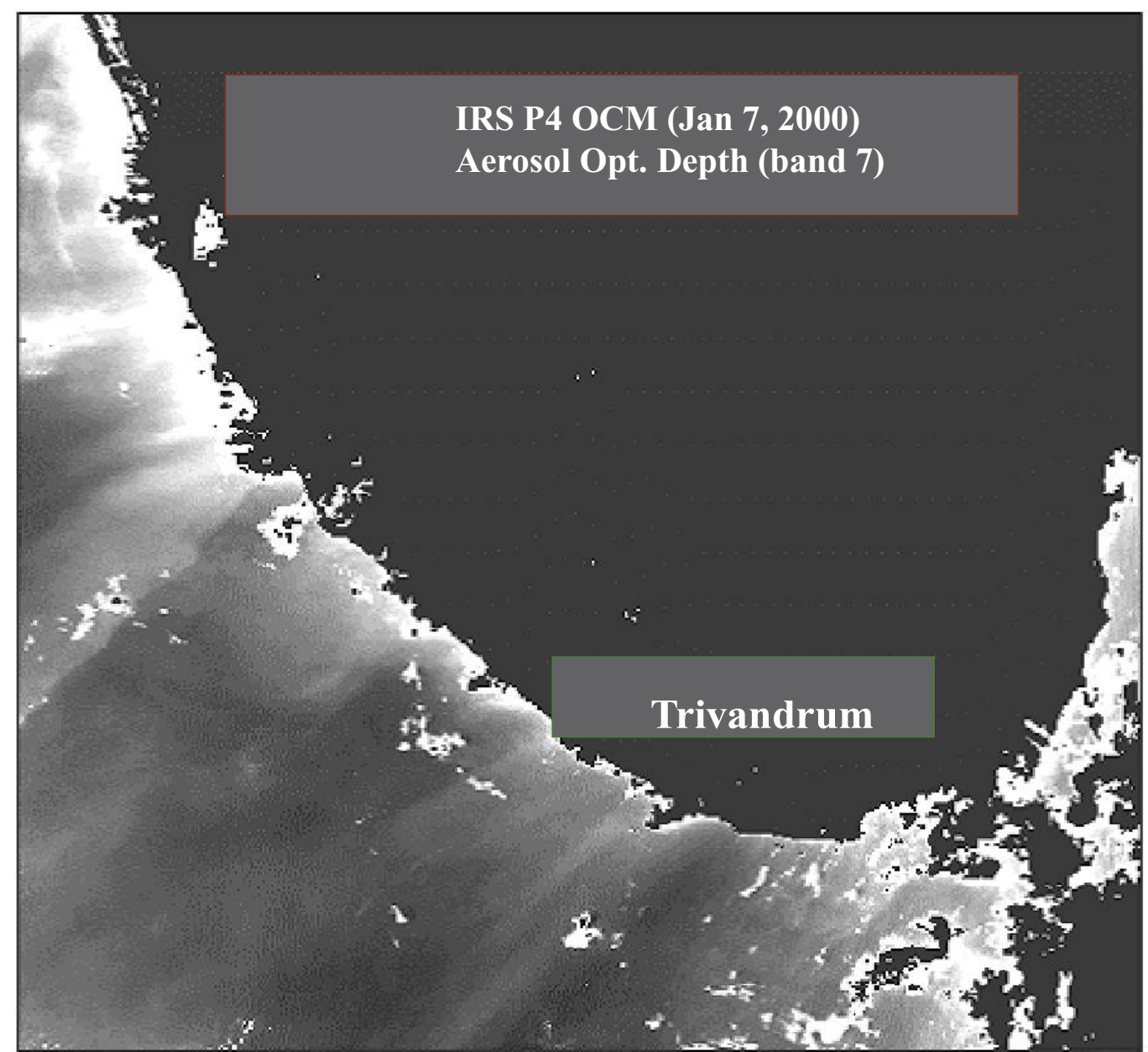

\section{MOGSAC:}

\section{$\mathbf{0 . 0}$}

0.5

Figure 3. Aerosol optical depth detected by IRS P4-OCM off Trivandrum coast on January 7th, 2000. The highly reflecting land surface and clouds are masked as dark. The irregular white patches are cloud edges or optically thin clouds.

spatial distribution of aerosols brought out by the high-resolution capability of the OCM sensor.

\section{Comparison between the OCM and NOAA derived AOD}

The National Environmental Satellite Data and Information Service (NESDIS) operationally derives Aerosol Optical Thickness (AOT) from the channels 1 and 2 of NOAA - AVHRR on a routine basis with an accuracy of $10 \%$ and archives for the global oceans (Husar et al 1997; Stowe et al 1997). The aerosol model used in this retrieval is a modified Junge particle size distribution (Junge 1958) given by

$$
\begin{aligned}
& \mathrm{d} N / \mathrm{d} r=0 \text { for } r<r_{\min } \text { and } r>r_{\max }, \\
& \mathrm{d} N / \mathrm{d} r=K \text { for } r_{\min } \leq r \leq r_{m},
\end{aligned}
$$

$$
\mathrm{d} N / \mathrm{d} r=K\left(r / r_{m}\right)^{-(\nu+1)} \text { for } r_{m} \leq r \leq r_{\max },
$$

where $r_{\min }, r_{m}, r_{\max }$ are $0.03,0.1$ and $10 \mu \mathrm{m}$ respectively, $\nu=3.5$ and $K$ is a normalisation constant decided by the number of particles per unit volume. The Angstrom exponent is 1.5 and single scattering albedo is 1.0. These data are available as aerosol optical depth at $630 \mathrm{~nm}$ averaged over 1 degree $\times 1$ degree (website: http://capita.wustl.edu/Databases/Userdomains/ Saharadust2000 ).

OCM derived AOD over the oceans (Arabian Sea and Bay of Bengal), averaged over 1 degree $\times 1$ degree boxes coinciding with the NOAA grids and with $<10 \%$ cloud cover were compared with the NOAA operational AOD. For this comparison, the NOAA - AOD was extrapolated to the OCM band7 wavelength as

$$
\tau_{a \mathrm{OCM}}=\left(\lambda_{\mathrm{OCM}} / \lambda_{\mathrm{NOAA}}\right)^{\alpha} \tau_{a \mathrm{NOAA}}
$$




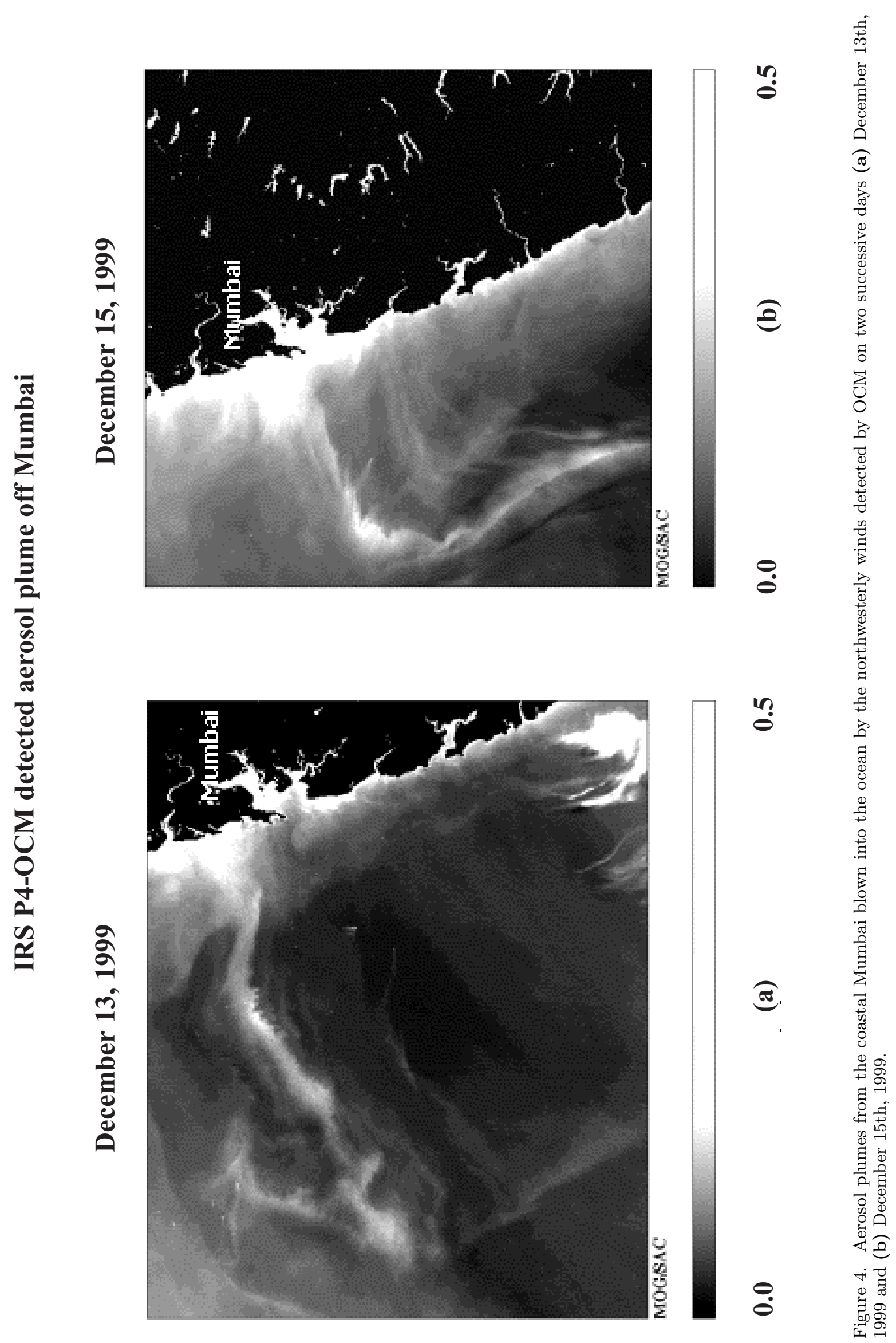




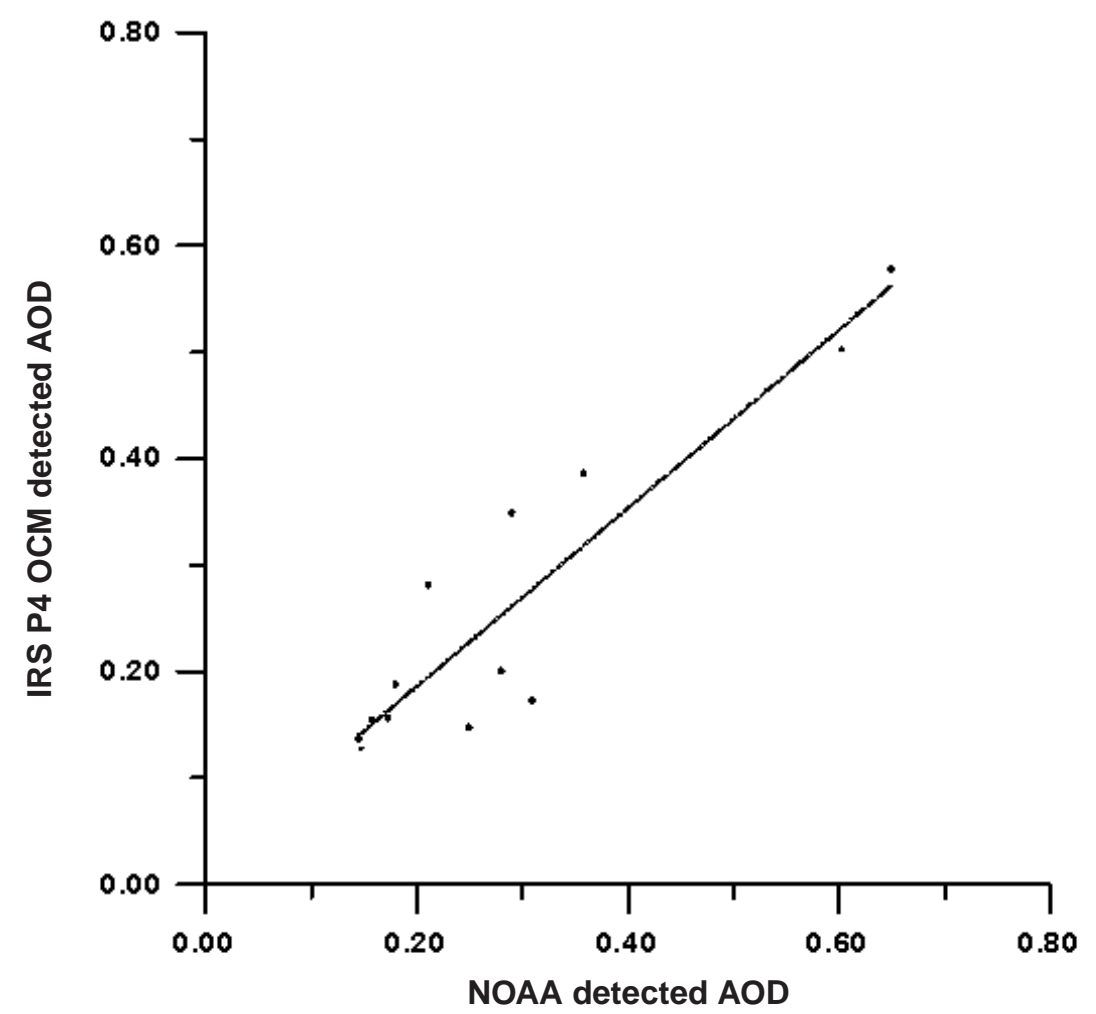

Figure 5. Scatterplot of OCM detected by AOD against the NOAA operational AOD at $630 \mathrm{~nm}$. The OCM-AOD has been degraded to $1^{\circ} \times 1^{\circ}$ to suit the NOAA resolution.

where

$\tau_{a \mathrm{OCM}}=\mathrm{AOD}$ at OCM band -7 wavelength,

$\tau_{a \mathrm{NOAA}}=\mathrm{AOD}$ at NOAA wavelength,

$\lambda_{\mathrm{OCM}}=$ OCM band 7 wavelength $(765 \mathrm{~nm})$,

$\lambda_{\text {NOAA }}=$ NOAA wavelength $(630 \mathrm{~nm})$,

$\alpha=$ Angstrom exponent.

Even though the Angstrom exponent used in the NOAA retrieval is 1.5 , we have used a value of 1.3 to agree with the marine aerosol model (Doerffer 1992, Satheesh et al 1999) used in the OCM retrieval. This discrepancy can incur a maximum error of $\sim 4 \%$ in the AOD derived using equation (12).

Figure 5 shows the scatterplot of OCM derived AOD against the NOAA derived AOD which follows a linear regression

$$
\tau_{a \mathrm{OCM}}=1.01 \tau_{a \mathrm{NOAA}}+0.026
$$

with a correlation 0.92 at a level of significance $0.10 \%$. Although a reasonably good correlation is achieved, points are found to lie far from the mean line. The spread of points about the straight line may be attributed to the deviations in the derived AODs arising from the difference in the aerosol models used in the two retrievals, difference in the times of pass of the two satellites and NOAA bands (channels 1 and 2) being broad $(>60 \mathrm{~nm})$ and affected by water vapour interference in the derived AOD.

\section{Comparison between the OCM derived AOD and ground measurements}

The OCM derived AOD were compared with ground based measurements at a coastal location at Trivandrum $\left(8.29^{\circ} \mathrm{N}, 76.59^{\circ} \mathrm{E}\right)$. The ground measurements were carried out with an MWR (Multi Wavelength Radiometer) with filters at the wavelengths $380,400,450,500,600,650,750,850$, 935 and $1025 \mathrm{~nm}$ (Krishnamoorthy et al 1997) synchronous with the satellite pass. From the AOD values of 750 and $850 \mathrm{~nm}$, the Angstrom Exponent $(\alpha)$ was determined for each day as

$$
\alpha=\left[\ln \left(\tau_{750}\right)-\ln \left(\tau_{850}\right)\right] /\left[\ln \left(\lambda_{850}\right)-\ln \left(\lambda_{750}\right)\right]
$$

and was used to compute the AOD for OCM wave length $765 \mathrm{~nm}$ using a relation similar to equation (12). The data of only those days in which cloud free measurements were available within 2 $3 \mathrm{hrs}$ of satellite pass were considered. On the corresponding days, the OCM derived AODs were taken over cloud free oceanic points closest to the location of the MWR but away from the coast by $\sim 5-6 \mathrm{~km}$ in order to avoid the bottom reflection and back scattering in the shallow and turbid coastal waters.

In figure 6 is shown the scatterplot of the OCM derived AOD against the ground measurements of 


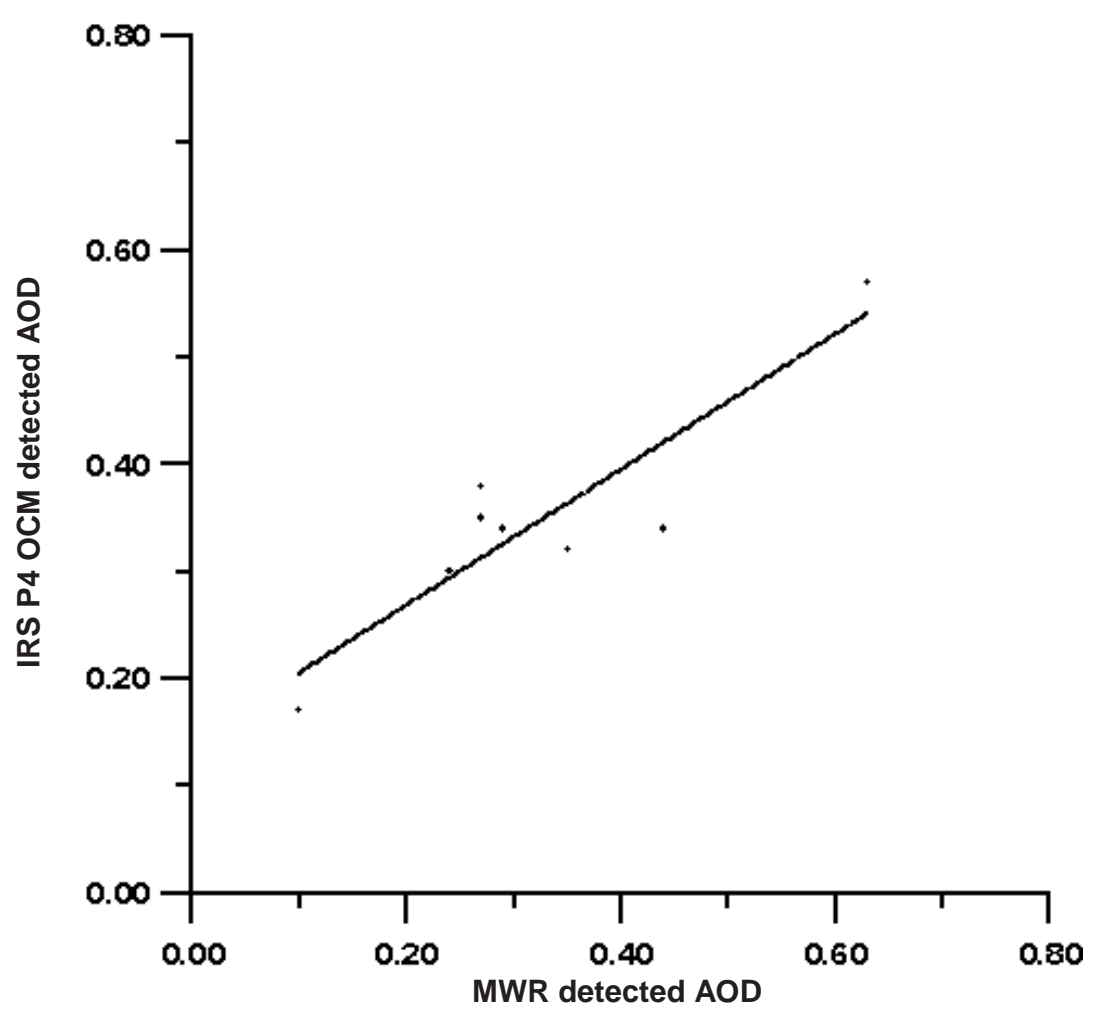

Figure 6. Scatterplot of OCM detected by AOD against the ground measurements by MWR near Trivandrum coast at $750 \mathrm{~nm}$.

MWR. The plot gives a correlation of 0.90 at a level of significance $0.35 \%$ and obeys the regression relation

$$
\tau_{a \mathrm{OCM}}=0.63 \tau_{a \mathrm{MWR}}+0.14
$$

\section{Conclusions}

An algorithm was developed to estimate the AOD of the marine aerosols from the atmospheric correction band 7 data of IRS P4-OCM. A sensitivity study carried out on this algorithm shows that the retrieved AOD is $\sim 100$ times more sensitive to $g_{1}$ than to $g_{2}$ of the HG phase function. A change -10 to $+10 \%$ in $g_{1}$ can bring about $-8.78 \%$ to $38.21 \%$ deviation in the derived AOD while a similar change in A can cause about $-1.31 \%$ to $1.35 \%$ deviation in AOD. In the case of $w_{0 a}$, a $10 \%$ decrease brings about an $11.11 \%$ increase in $\mathrm{AOD}$ and as far as $L_{a}$ is concerned, any error in it produces a directly proportional deviation in AOD.

The high resolution aerosol images of OCM bring out a number of details in the spatial distribution of aerosols and the effect of prevailing winds on aerosols very clearly. The OCM derived AOD has been found to agree with the NOAA detected AOD with a correlation 0.92 (at a significance level $0.10 \%$ ) and with the ground measurements at
Trivandrum coast with a correlation 0.90 (at a significance level $0.35 \%$ ).

Ocean colour sensors can be very effective tools for the study of phenomena like aerosol transport, effects of wind and relative humidity on aerosols, cloud generation by aerosols acting as condensation nuclei, etc. over the oceans where ground observations are difficult. Even though the accuracy of satellite retrieval of AOD is not presently very high in comparison with ground measurements, this will be improved through extensive comparisons of satellite derived AOD with the ground measurements and by modifying aerosol models in the retrieval algorithm to suit different regions, seasons, wind conditions, relative humidity, etc.

\section{Acknowledgements}

The authors are grateful to the ISRO-Geosphere Biosphere Programme for financial support for carrying out the research reported in this work.

\section{References}

Charlson R J, Lovelock J E, Andreae M O and Warren S G 1987 Oceanic phytoplankton, atmospheric sulpher, cloud albedo and climate; Nature $\mathbf{3 2 6} 655-661$ 
Coakley J A, Cess R D and Yurevich F B 1983 The effect of tropospheric aerosols on the earth's radiation budget: A parameterisation for climate models; J. Atmos. Sci. 40 $116-138$

Doerffer R 1992 Imaging spectroscopy for detection of chlorophyll and suspended matter; In: Imaging Spectroscopy: Fundamentals and Prospective Applications; (eds) F Toselli and J Bodechtel (Dordrecht/Boston/ London: Kluwer Academic Publishers) 215-257

Galindo I 1984 Anthropogenic aerosols and their regional scale climatic effects, In: Aerosols and their climatic effects (eds) H E Gerber and Deepak Adarsh (A. Deepak Publishing) 245-273

Gordon H R 1997 Atmospheric correction of ocean colour imagery in the Earth Observing System era; J. Geophys. Res. 102 17081-17106

Husar R B, Prospero J M and Stowe L L 1997 Characterisation of tropospheric aerosols over the oceans with NOAA advanced very high resolution radiometer optical thickness operational product; J. Geophys. Res. 102 No. D 14, $16,889-16,909$

McClain C R, Evans R H, Brown J W and Darzi M 1995 SeaWiFS quality control masks and flags: Initial algorithms and implementation strategy; SeaWiFS Technical Report Series, 28 (SeaWiFS Algorithms, Part1), NASA Tech. Memorandum 104566, 3-7

Joseph J H 1984 Gaps in the knowledge of aerosols - analysis and remedies, In: Aerosols and their climatic effects, (eds) H E Gerber and Deepak Adarsh (A. Deepak Publishing) $275-278$

Junge C E 1958 Atmospheric Chemistry; Adv. Geophys. 4, $1-108$
Kaufman Y J, Tanre D, Gordon H R, Nakajima T, Lenoble J, Frouin R, Grassl H, Herman B M, King M D and Teillet P M 1997 Passive remote sensing of tropospheric aerosol and atmospheric correction for the aerosol effect; J. Geophys. Res. 102 No. D14, 16, 815-16, 830

Krishnamoorthy K, Satheesh S K and Krishna Moorthy B V 1997 Investigations of marine aerosols over the tropical Indian Ocean; J. Geophys. Res. 102, No. D15, 18, 82718,842

Penner J E, Andreae L, Annegarn H, Barrie L, Feichter J, Hegg D, Jayaraman A, Leaitch R, Murphy D, Nganga J and Pitari K 2001 Radiative forcing of climate change; IPCC, 378-405

Stowe L L, Ignatov A M and Singh R R 1997 Developments, validation and potential enhancements to the second generation operational aerosol product at NOAA/NESDIS; J. Geophys. Res. 102, No. 14, 16, 92316,924

Satheesh S K, Ramanathan V, Li-Jones Xu, Lobert J M, Podogomy I A, Prospero J M, Holben B N and Loeb N G 1999 A model for the natural and anthropogenic aerosols over the tropical Indian Ocean from Indian Ocean Experiment; J. Geophys. Res. 104, No. D22, 27, 421-27, 440.

Sturm B 1980 The atmospheric corrections of remotely sensed data and the qualitative determination of suspended matter in marine water surface layers, In: Remote sensing in meteorology, oceanography and hydrology, (ed) A P Cracknell, (Ellis Horwood Ltd., Chichester) 163-197

WMO (World Meteorological Organisation) 1996 WMO and Climate change, WMO Rep. No. 848 